\title{
Spatiotemporal characteristics of serial CSs and their relation to search modes and response form
}

\author{
FRANCISCO J. SILVA, WILLIAM TIMBERLAKE, and RORY S. GONT \\ Indiana University, Bloomington, Indiana
}

\begin{abstract}
In four experiments, we examined how the spatiotemporal proximity to food of the two elements of a serial conditioned stimulus (CS) influenced the pattern of CS-directed versus food-site-directed behavior in rats. Experiment 1 showed that only temporal proximity affected responding when the serial CS consisted of two successive 4-sec presentations of either a spatially near or a spatially far lever (NN or FF). However, Experiment 2 showed that behavior depended markedly on whether rats received a near followed by a far lever (NF) or a far followed by a near lever (FN). Experiment 3 showed that the effects of Experiment 2 could be changed by increasing the duration of the second CS element, and Experiment 4 showed that these changes were not related to previous training. We concluded that behavior produced by the spatiotemporal qualities of the lever elements can be attributed to a mapping between the temporal qualities of the CS elements and an underlying sequence of search modes related to finding food.
\end{abstract}

Given a choice, animals generally prefer cues that are more spatially and temporally proximate to food (Bowe, 1984). For example, rats quickly learn to choose the location of the rewarded arm of a T-maze (Kimble, 1961; Terrace, 1984), and pigeons differentially peck a key that is more likely to produce reward in a short time (Baum, 1974; Herrnstein, 1970). These results fit well with traditional reinforcement and reward-following models of learned behavior in which responses are strengthened as a direct function of their spatial and temporal proximity to food (see, e.g., Hull, 1952; Staddon \& Horner, 1989). These results also fit with optimal foraging models that presume that foraging animals maximize benefit per cost and behave so as to minimize their delay in obtaining food (Stephens \& Krebs, 1986).

The applicability of reward-following and optimality models is less clear when animals "misbehave" by emitting responses that are unnecessary (e.g., superstitious behavior-Skinner, 1948; Staddon \& Simmelhag, 1971; Timberlake \& Lucas, 1985) or that interfere with obtaining reward (e.g., automaintenance-Williams \& Williams, 1969; constraints-on-learning-Sevenster, 1973; misbehavior-Breland \& Breland, 1961). The frequent emergence of such stereotyped, inefficient responses suggests that behavior in the presence of food is influenced by preorganized characteristics of the organism as well as by

This research was supported by NSF Grants IBN-9121647 and 9408366. We thank Kathleen Silva for comments and suggestions on an earlier draft of this manuscript and Jessica Cutrera and Tammi Nelson for their help with the data collection. Please address correspondence to F. J. Silva, now at the Department of Psychology, University of Redlands, 1200 East Colton Avenue, P.O. Box 3080, Redlands, CA 92373 0999 (e-mail: silva@uor.edu) or W. Timberlake, Department of Psychology, Indiana University, Bloomington, IN 47405 (e-mail: timberla@ indiana.edu). the spatial and temporal proximity of reward (Timberlake, 1993). One such contribution of the organism appears in the form of typical perceptual-motor organization that facilitates reliable but potentially inefficient responses to particular stimuli (Timberlake \& Lucas, 1989). For example, an important basis for the emergence of rooting in pigs trained to carry tokens to a "bank" to obtain food (Breland $\&$ Breland, 1961) appears to be a species-typical digging response related to foraging for roots (see Mason, 1991).

In addition to specific perceptual-motor organization, a second contribution of the organism in determining responding may involve a sequence of preorganized motivational modes that underlies strings of responses preceding and following food (Lucas, Timberlake, \& Gawley, 1988; Timberlake, 1994; Timberlake \& Lucas, 1991; see also Craig, 1918; Tinbergen, 1951). In this view, hungry animals in the absence of proximate food cues are most strongly controlled by a general search mode that influences stimulus sensitivities and by response components related to systematically searching the environment for food (see Figure 1). The receipt of cues that are better predictors of food differentially activates a focal search mode that controls more specifically food-related stimulus sensitivities and responses such as digging, capturing, and manipulating. Finally, the presence of food strongly activates a handling/consuming mode that supports responses involved in ingestion or storage. Immediately following food, the animal reenters a form of focal search (i.e., postfood focal search).

In short, each motivational mode is hypothesized to sensitize perceptual-motor mechanisms appropriate to foraging at a particular spatiotemporal proximity to food. The transition from a more distant to a more proximate mode is controlled by encounters with stimuli that signal an increase in the spatiotemporal proximity of food on the basis of a combination of individual and evolution-based 


\section{CONTINUUM OF SEARCH MODES}

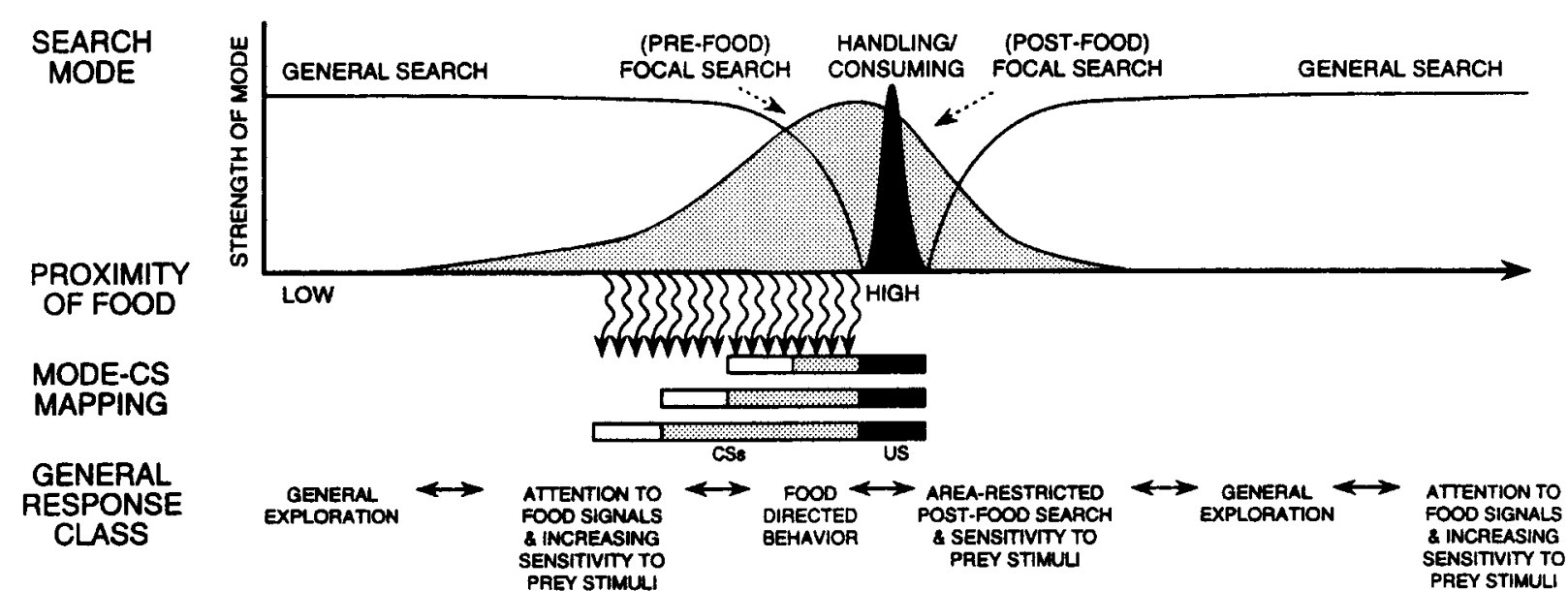

Figure 1. A representation of the sequence of search modes related to procuring and ingesting food, the associated general response classes, and the mapping between the search modes and stimuli in the environment. Note that, with a serial conditioned stimulus (CS), the first serial element (represented as the light gray rectangle in the figure) is mapped to earlier aspects of the focal search mode than is the second element (the dark gray rectangle), which is mapped to later aspects of the focal search mode. Increasing the duration of the second element causes its mapping to shift from late to early focal search/late general search.

experience. Thus, a hungry rat exposed to a flashing light previously paired closely with food should enter a focal search mode, as should a hungry naive rat when a moving stimulus contacts its whiskers.

In this behavior systems view, Pavlovian training results in a mapping between one or more search modes and the conditioned stimulus (CS; see also Konorski, 1967). The relative strength of the different modes controlled by a CS should be determined by its spatial and temporal proximity to food, its evolution- and experience-based perceptual characteristics, and the context (Akins, Domjan, \& Gutiérrez, 1994; Domjan, 1994; Timberlake, 1994). For example, in the case of a moving stimulus predicting food for hungry rats (such as a rolling ball bearing, see Timberlake, Wahl, \& King, 1982), both a relatively long interval between the CS and the unconditioned stimulus (US) and the distant movement of the CS most strongly support a general search mode, whereas the proximity and size of the CS and its manipulability support a focal search mode. This combination of general and focal search modes will support the conditioning of a sequence of responses, such as attending to, tracking, chasing, and capturing the moving stimulus, followed by manipulation and biting (K. M. Silva \& Timberlake, 1997). A shorter CS-US interval with the same moving stimulus will best support conditioning of focal search and handling/consuming modes and their related responses, such as intense nosing and digging at the food site (Timberlake et al., 1982).

The purpose of the present experiments was to use a serial conditioning procedure with identical CS elements (insertable levers differing only in their spatiotemporal relation to food) to examine the circumstances under which spatial and temporal cues control responding to the lever versus responding to the food site. We were particularly interested in exploring the relation of responding to the hypothesized sequence of underlying search modes (see, e.g., F. J. Silva, Timberlake, \& Cevik, 1998; F. J. Silva, Timberlake, \& Koehler, 1996; K. M. Silva \& Timberlake, 1997; Timberlake \& K. M. Silva, 1995). At the same time, we considered predictions and explanations offered by a more traditional associative approach.

The serial CS procedure allowed us to separately manipulate the spatial and temporal proximity of the CS to food. In Experiment 1, we presented two groups of rats with a serial CS consisting of two brief (4-sec) presentations of identical levers that were located either "far" from or "near" the food site. The quotation marks (" ") are used because the actual difference in distance to the food site from the levers was quite small $(2.5 \mathrm{~cm})$. In Experiment 1 , we assessed the extent to which the spatial and temporal proximity of the levers independently controlled the distribution of responses directed to the levers and the food site. In Experiment 2, we contrasted the behavior systems framework with a more traditional associative approach by comparing behavior during a serial CS composed of stimuli that were spatiotemporally most congruent with chasing and capturing a prey item (the far lever was followed by the near lever, then by food) with a serial CS composed of stimuli spatiotemporally more incongruent with chasing and capturing a prey item (the near lever was followed by the far lever, then by food). In Experiment 3, we examined the effect of increasing the duration of the second stimulus on the distribution of responses during congruent and incongruent serial CSs, 
and in Experiment 4, we tested the contribution of prior experience to the effects of the duration manipulation.

\section{EXPERIMENT 1}

In Experiment 1, we attempted to establish the contribution of two successive 4-sec presentations (insertions followed by withdrawals) of either a far lever (Group FF) or a near lever (Group NN) to the form of responding that emerged. The order of the uppercase letters denotes the temporal sequence in which the two levers were presented, and the letter itself denotes whether the lever was spatially far or near to the food site. Thus, for Group FF, the first lever was both spatially and temporally distant from food, and the second lever was spatially far but temporally proximate. For Group NN, the first lever was temporally distant but spatially near, whereas the second lever was both spatially and temporally proximate. It is important to reiterate that the terms near and far are relative, defined by a difference in distance of only $2.5 \mathrm{~cm}$ between the lever CSs and the food site.

At a conceptual level, we were concerned with how the spatiotemporal parameters of two successive presentations of the same lever coordinated with the sequence of search modes posited by the behavior systems approach. On the basis of our previous experience with CS-US intervals involving discrete moving cues, the first lever should gain better control of a late general search state based on the conditioning of both general and focal search modes, thereby facilitating attention, chasing, contact, and some manipulation responses directed toward the lever. The second lever should gain better control of a focal search state, combining focal search and handling/ consuming modes, thereby facilitating nosing and digging at the food site (see Figure 1).

Given this mapping between search modes and CS elements, we expected three outcomes: (1) more lever contact during the presentation of the first (temporally distant) stimulus than during the presentation of the second (temporally proximate) stimulus, on the basis of the assumption that the temporally distant stimulus should come to control a late general search state (a combination of general and focal search modes); (2) more nosing in the food site during the presentation of the second stimulus, on the basis of the assumption that this stimulus should come to control a focal search state (a combination of focal and handling/consuming modes); and (3) no effect of the spatial proximity of the levers to the food site. This last prediction was based on the small, $2.5-\mathrm{cm}$ difference in the distance of the near and far levers to the food site. A given rat had no basis for comparing the distances of the near and far levers, because both serial elements were the same lever (either FF or NN).

A more traditional associative view of these circumstances makes one prediction similar to that of the behavior systems approach - that a vigorous conditioned response (CR) should emerge during that CS element most temporally proximate to the US. A different prediction is that the more distant element should control weaker and even possibly inhibitory CRs (Kehoe \& Napier, 1991). Unspecified in the predictions of a more traditional associative view is what form the CR should take and, if more than one CR emerges, what their relative expression should be. Put simply, traditional associationism deals with the concept of associative strength without trying to specify the form of the CR (with the exception of the stimulus substitution approach, which has been of limited use at all but the shortest CS-US intervals-see Domjan, 1994). Thus, although the associative view predicts that the CR should be strongest in the most proximate element, it is unclear whether this applies to nosing in the food site or contacting the lever.

In sum, the behavior systems view envisions a sequence of CRs and attempts to account for their form and relation to the CS elements by the extent to which each CS controls different search modes and the environment supports the related perceptual-motor repertoire. A specific point of contrast with a more traditional associative approach is that the behavior systems view argues that different, rather than just weaker, responses should be conditioned to a more distant CS (Akins et al., 1994; Domjan, 1994; F. J. Silva et al., 1996).

\section{Method}

Subjects. The animals were 16 female Sprague-Dawley (Rattus norvegicus) rats that were approximately 90 days old at the start of the experiment. The rats were maintained at $85 \%$ of their free-feeding weights throughout the course of the experiment, and they were housed in individual cages in a colony room regulated by a $12: 12-\mathrm{h}$ light:dark cycle. Water was freely available in the home cages.

Apparatus. The apparatus consisted of four metal rectangular boxes $(50 \times 36 \times 32 \mathrm{~cm})$ with Plexiglas fronts and tops. Each box was contained in a sound-attenuating wood chamber and dimly illuminated by a $25-\mathrm{W}$ light bulb oriented toward the ceiling. A fan located at the back of each chamber provided masking noise and ventilation.

Food pellets (Bio Serv 45-mg dustless pellets; Frenchtown, NJ) were delivered by a Waltke Feeder (Bloomington, IN) into a metal food tray located in a recessed opening on the back wall of the box. The food site aperture was $3.2 \mathrm{~cm}$ wide and was located $19.5 \mathrm{~cm}$ from the right sidewall, $15 \mathrm{~cm}$ from the left sidewall, and $5 \mathrm{~cm}$ above the floor. An infrared photodetector measured each time the subject placed its head in the food tray. The touch-sensitive near retractable lever was located $4 \mathrm{~cm}$ from the left side of the food receptacle, and the touch-sensitive far lever was located $6.5 \mathrm{~cm}$ from the right side of the food receptacle. Both levers were located $4.5 \mathrm{~cm}$ above the floor. Both levers were $3.7 \mathrm{~cm}$ wide. Lever contacts were detected when a rat standing on the floor completed an electrical circuit by touching a lever. All measures from the food site to the levers were taken from nearest edge to nearest edge.

The apparatus was controlled by an IBM-PC and solid state interface located in an adjacent room. Programmed contingencies and data collection were managed at a $0.1-\mathrm{sec}$ resolution, using Conman Contingency Management Software (Spyder Systems, Bloomington, IN).

Procedure. The 16 rats were divided into two groups of 8 , equated for their ad-lib weights. Experimental sessions occurred 6 days a week at approximately the same time each day. Rats were weighed before each session and, after the session, fed a supplemental amount of food to maintain their weights at $85 \%$ ad lib. The rats were fed at the same time on the 7 th day. The order of groups was alternated each day to eliminate any time bias. Each session consisted of 12 trials. The interfood interval (IFI) averaged $90 \mathrm{sec}$, with 

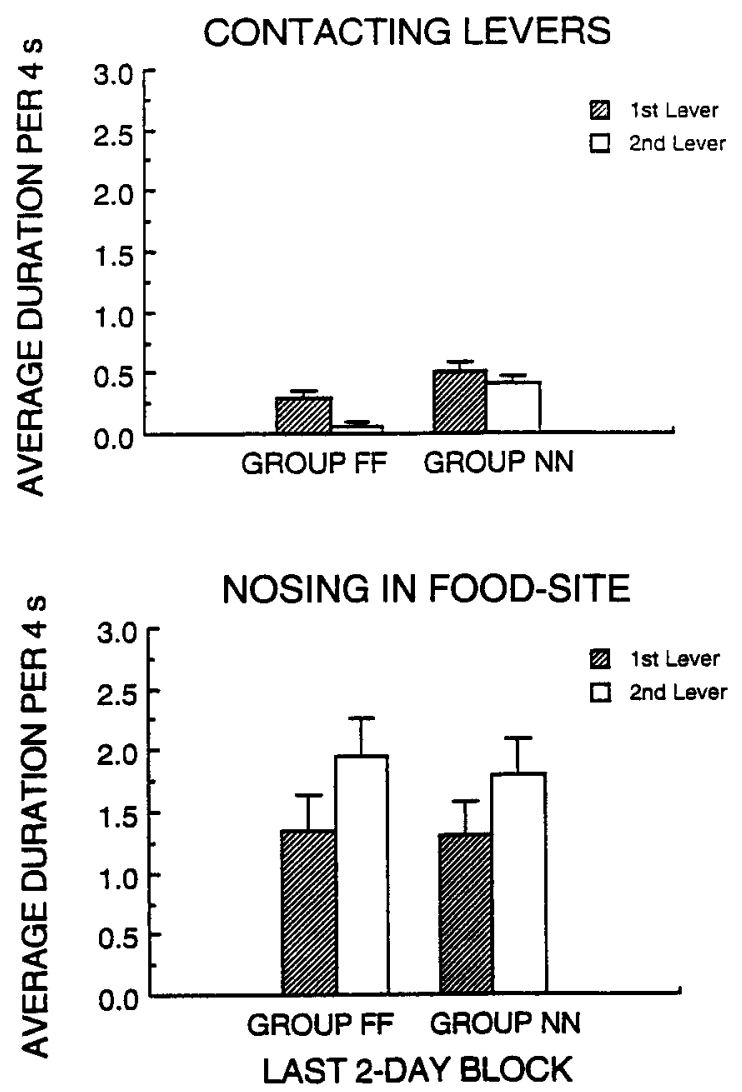

Figure 2. The average duration ( $\pm S E M$ ) spent contacting the far and near levers (top panel) and nosing in the food site during the presentation of the far and near levers (bottom panel) per 4 sec for Groups FF and NN in Experiment 1.

a range between 60 and $120 \mathrm{sec}$. The experiment proceeded through the following stages: chamber adaptation, pretraining (feeder training), and serial conditioning.

Before actual training took place, each group was placed in the boxes for approximately $20 \mathrm{~min}$ in order to reduce neophobia to the experimental environment. After this chamber adaptation phase, the rats were feeder trained by placing them in the chambers for a 20-min session, during which approximately 24 food pellets (i.e., 2 pellets per trial $\times 12$ trials) were delivered. On the 2 nd day, the rats that did not eat the food on the 1st day were trained again, using the same procedure as the 1 st day.

During the subsequent serial-conditioning phase, both groups of rats were trained with a serial CS predicting food, which was presented on a variable time (VT) $90-\mathrm{sec}$ schedule. All trials consisted of successive 4-sec presentations of the far lever, followed by a second 4-sec presentation of the far lever (Group FF), or of the near lever, followed by a second presentation of the near lever (Group $\mathrm{NN}$ ). The timing of the lever presentation began as soon as the lever began to enter the chamber. It took approximately $0.5 \mathrm{sec}$ for a lever to be completely inserted into or withdrawn from the chamber. Food followed the retraction of the second lever for both groups. This conditioning procedure lasted for 12 sessions. The dependent measures consisted of the amounts of time the rats spent contacting the levers and nosing inside the food site during presentation of the levers. We followed the convention of determining statistical significance if the results of a statistical test were $p<.05$, but we also followed the contemporary practice of referring to results just slightly above .05 as marginally significant (see the discussion in Aron \& Aron, 1994, and in Howell, 1997).

\section{Results and Discussion}

The top graph in Figure 2 shows the average duration spent contacting the levers for Groups FF and NN during the last 2-day block of conditioning. An analysis of variance (ANOVA) confirmed that the two groups did not differ in the amount of time they spent contacting the levers $[F(1,14)=0.80]$ and that, although there was little contact to either lever, the combined groups reliably contacted the first lever more than they did the second lever $[F(1,14)=7.84]$.

The bottom graph in Figure 2 shows the average duration spent nosing in the food site during the last 2-day block of conditioning. An ANOVA confirmed that the two groups did not differ in the amount of time they spent nosing in the food site $[F(1,14)=0.07]$, but they did nose in the food site more during the presentation of the second (temporally proximate) lever than during the presentation of the first (temporally distant) lever $[F(1,14)=34.25]$.

In sum, the results from Experiment 1 showed that there was more nosing in the food site during the presentation of the second (temporally proximate) lever than during the presentation of the first (temporally distant) lever and more contact of the first lever than of the second. Further, within the parameters of the present experiment, the absolute spatial distance of the lever from the food site did not affect either nosing in the food site or contacting the lever. Thus, the temporal sequence of presentations of a repeated CS element was an important determinant of responding, but the spatial distance of the CS elements from the food site was not.

These results are consistent with the behavior systems approach and, to an extent, with a more traditional associative view. The behavior systems view presumes that the more temporally distant $\mathrm{CS}$ element controlled both general and focal search modes, whereas the more temporally proximate CS element controlled focal and handling/ consuming modes. On the basis of our previous work in similar circumstances (F. J. Silva et al., 1996; K. M. Silva \& Timberlake, 1997; Timberlake et al., 1982), this mapping between modes and CSs means that the first CS element should better control approach and contact directed to the lever, whereas the second CS element should control more nosing in the food site. The present results support this view.

According to a more traditional associative account, each element of a serial CS acquires its own associative strength in direct relation to its temporal proximity to the US. The strongest CR should emerge during the presentation of the element most proximate to the US, and more distant elements should control weaker and possibly inhibitory CRs (Kehoe \& Napier, 1991). The nosing in the food site data were consistent with this analysis, but the lever contact data were not. However, it could be argued that the different responses (nosing in the food site and contacting the lever) had different optimal CS-US inter- 
vals (see, e.g., Schneiderman \& Gormezano, 1964). Thus, the optimal conditioning interval for nosing in the food site could be shorter than the optimal interval for contacting the lever (see also Konorski, 1967).

Although a multiple optimal-interval account might explain why there was more approach and contact of the lever during the presentation of the first CS element and more nosing in the food site during the presentation of the second CS element, this account lacks the conceptual development to explain a priori why there were multiple CRs and how they should map to the elements of the serial CS. We will consider further differences between the behavior systems and associative views in the next experiment.

\section{EXPERIMENT 2}

The first experiment showed both the importance of the temporal sequence of CS elements in determining responding and the lack of importance of the small absolute difference in their spatial distance to food. However, in most learning circumstances, there is a correlation between spatial and temporal distance in the sequence of predictive stimulus elements. For example, in maze learning, Tolman (1932) noted that the spatially shortest path to reward typically also was the temporally quickest, thereby correlating these two dimensions in a congruent spatiotemporal sequence of stimuli as the rat solves the maze.

To clarify the contribution of spatial and temporal dimensions acting together, Experiment 2 compared a group receiving a congruent sequence of CS elements (i.e., their relative spatial proximity to the food site was positively correlated with their temporal proximity to food delivery) with a group receiving an incongruent sequence of CS elements (their relative spatial proximity to the food site was negatively correlated with their temporal proximity to food delivery). Specifically, the congruent Group FN received a serial CS in which the far lever was followed by the near lever. For this group, the spatially far stimulus was also the most temporally distant, and the spatially near stimulus was the most temporally proximate. The incongruent Group NF received a serial CS in which the near lever was followed by the far lever. In this case, the spatially nearer stimulus was the most temporally distant, whereas the spatially far stimulus was the most temporally proximate.

It is worth noting that, in the present experiment, both the congruent and incongruent sequences of CS elements involved similar spatial patterns of presentation relative to the food site. The first lever was presented for $4 \mathrm{sec}$ on one side of the food site, the second lever was presented for $4 \mathrm{sec}$ on the other side of the food site, and then food was delivered. In both cases, an animal approaching the second lever had to go past the food site. The difference was that, in the congruent sequence (FN), the second lever was $2.5 \mathrm{~cm}$ closer to the food site than was the first lever, thus creating a positive correlation between spatial and temporal distance, whereas in the incongruent sequence (NF), the second lever was $2.5 \mathrm{~cm}$ farther from the food site than was the first lever, thus creating a negative correlation between spatial and temporal proximity. The question we were interested in answering was, Would the rats react to these small differences in the relative proximity of the second lever to the food site?

From a more traditional associative view, it seems unlikely that the small difference in the distance of individual CS elements from the food site should strongly affect responding. Given that there was no effect of the absolute spatial distance of the second lever element from the food site in Experiment 1, we would expect the results of both Group FN and Group NF to resemble the temporal effects obtained in Experiment 1 (i.e., more lever approach and contact during the presentation of the first CS element than during the presentation of the second, and more nosing in the food site during the presentation of the second CS element than during the presentation of the first).

However, if the small spatial differences between the two lever elements does have an effect, the rats in the congruent Group FN would be likely to exaggerate the differences in responding to the two CS elements, because the first lever is now both temporally and spatially more distant from the US than the second lever. In contrast, for the incongruent Group NF, responding should be more similar during the presentation of the two lever elements because both the first and second elements are a mixture of near and far spatial and temporal components from food. The first element is temporally far but spatially near; the second element is temporally near but spatially far.

As in the last experiment, there is a problem in predicting the relative amount of nosing in the food site and contacting the lever. If we assume that contacting the lever and nosing in the food site have optimal spatial intervals for conditioning (in addition to optimal temporal intervals), we predict that the effect of the far-near spatial differences in the present experiment should parallel the effect of the temporal differences shown in Experiment 1 . Thus, Group FN might show even more lever responding to the first stimulus and nosing in the food site to the second stimulus because the first CS element was both spatially and temporally appropriate for optimal conditioning of lever contact, whereas the second element was both spatially and temporally appropriate for optimal conditioning of nosing in the food site.

Using similar arguments, Group NF should show a more equal distribution of lever contact and nosing in the food site across the two CS elements because both elements contain both long and short CS-US "intervals." The first element is temporally distant and spatially proximate; the second element is temporally proximal and spatially distant. Thus, both CS elements should produce more similar amounts of contacting the lever and nosing in the food site.

The predictions of the behavior systems approach differ in that they emphasize the animal's ecology and resultant specializations. Rats are a predatory species with sensory-motor and motivational adaptations for chasing and capturing moving prey (Timberlake et al., 1982). They should be sensitive to the spatial differences in the two 

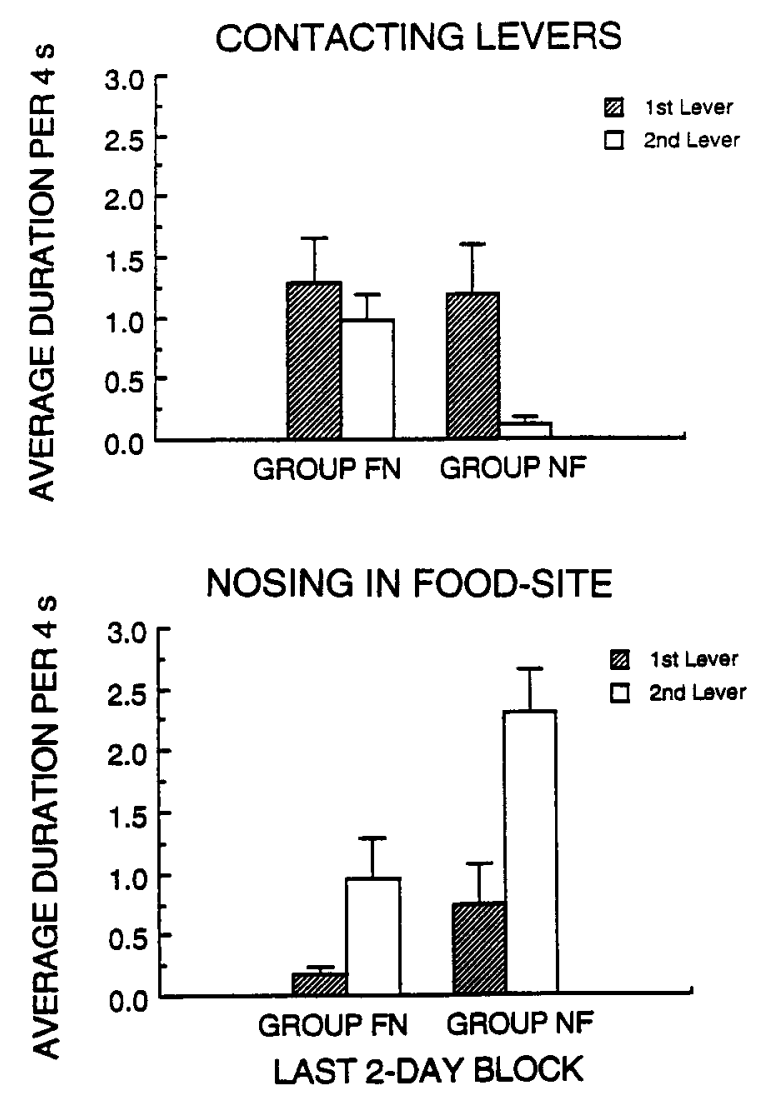

Figure 3. The average duration ( $\pm S E M$ ) spent contacting the far and near levers (top panel) and nosing in the food site during the presentation of the far and near levers (bottom panel) per 4 sec during the congruent stimulus (Group FN) and the incongruent stimulus (Group NF) in Experiment 2.

lever elements, not only because of their spatial and temporal proximity to food, but because of the potential mapping of the moving CS elements to predatory mechanisms involved in the chasing and capture of moving prey.

We know that rats show considerable approach to and interaction with a ball bearing rolling toward a food site when the bearing-US interval is greater than $4 \mathrm{sec}$ (Timberlake et al., 1982). At a bearing-US interval of $2.5 \mathrm{sec}$, however, rats predominantly fail to approach the bearing, instead treating it as a signal to nose in the food site. We also know from previous pilot data that a ball bearing moving away from the food site is less effective in producing chasing (see Timberlake, 1980). These results suggest that a manipulable stimulus moving toward the site of "capture" will condition a sufficiently strong general search mode to facilitate approach to and contact of the stimulus at CS-US intervals down to at least $4 \mathrm{sec}$. But the same moving stimulus presented with a CS-US interval of $2.5 \mathrm{sec}$ or moving away from rather than toward the food site appears to condition a stronger focal search mode that overcomes the eliciting qualities of the rolling bearing and produces more nosing in the food site than approaching the ball bearing.
Applying this analysis to the present circumstance suggests that, for Group FN, the sequential movement of the two levers in spatial locations successively closer to the capture site may engage the same general search mode prey-chasing mechanism as the ball bearing moving toward the food site. If this is the case, we would expect approach to and contact with both the first and second levers. Nosing in the food site would be expected to emerge during the presentation of the second lever element as the temporal proximity of food approaches $2 \mathrm{sec}$.

In contrast, for Group NF, the sequential movement of the two levers is similar to a ball bearing moving away from the capture site. The first lever should elicit the general search mode, characterized by approach to moving stimuli, but, because the second lever is farther from the food site, it will not sufficiently engage the preychasing mechanism of the general search mode when moving away from the food site at such a close temporal proximity to food (as with the ball bearing example described above). The result should be a reduced conditioning of a general search mode and a greater preponderance of nosing in the food site, supported by the conditioning of a focal search mode.

Stated in intuitive terms, the spatiotemporal characteristics of the FN stimulus map well with a rat's prey-chasing mechanisms because the cues signaling food get spatially closer to food as the arrival of food becomes more temporally imminent. Thus, we would expect chase and contact of both the first and second levers, followed by approach to the food site, during the presentation of the second lever. In contrast, the spatiotemporal characteristics of the NF stimulus map less well with the rat's preychasing mechanisms, because cues predicting food get spatially more distant as food becomes more imminent. On this basis, we would expect approach to the first lever, but a preponderance of approach to the food site during the presentation of the second lever as the stimulus predicting food leads away from the capture point. Both associative and behavior system predictions are tested in this experiment by a set of planned comparisons between groups and across CS elements within groups.

\section{Method}

Subjects. The animals were 16 female Sprague-Dawley rats that were approximately 90 days old at the start of the experiment. The housing conditions were the same as those used in Experiment 1.

Apparatus and Procedure. The apparatus, general procedures, and dependent measures were the same as those used in Experiment 1. Unlike in Experiment 1, however, all conditioning trials consisted of successive 4-sec presentations of the far lever, followed by the near lever (Group FN), or of the near lever, followed by the far lever (Group NF). This conditioning procedure lasted for 12 sessions.

Although we report factorial ANOVA results, the standard comparisons are not well suited to test the predictions of the approaches we are comparing. We were not primarily concerned with the main effects of spatial or temporal proximity or even with the overall interaction between spatial and temporal proximity of the $\mathrm{FN}$ and NF sequences. Instead, our focus was on the comparisons that comprise the interaction. Thus, we used $t$ tests to examine the statistical significance of these planned comparisons. 


\section{Results and Discussion}

The top graph in Figure 3 shows the average duration spent contacting the levers during the last 2-day block of conditioning. An ANOVA confirmed that both groups spent similar amounts of time contacting the levers [i.e., main effect of group, $F(1,14)=2.96$ ], regardless of the order in which the levers were presented [i.e., main effect of order, $F(1,14)=1.30$ ]. Although not statistically significant, there was a reasonably strong relation between the groups factor and the order of presentation $[F(1,14)=$ $4.31, p<.06$ ]. As is indicated in Figure 3, a planned comparison confirmed that Group NF contacted the first lever considerably more than it did the second $[t(7)=$ $2.44]$ but Group FN did not $[t(7)=0.62]$, and that, in the case of the second lever, the rats contacted the near lever (Group FN) much more than they did the far lever [Group NF; $t(14)=3.64]$.

The bottom graph in Figure 3 shows the average duration spent nosing in the food site during the last 2-day block of conditioning. An ANOVA confirmed that both groups nosed in the food site more during the presentation of the second (temporally proximate) lever than during the presentation of the first (temporally distant) lever $[F(1,14)=37.07]$ and that Group FN nosed in the food site less than did Group NF $[F(1,14)=7.08]$. Although not statistically significant, there was again a reasonably strong relation between group and the order in which the levers were presented $[F(1,14)=4.04, p<.06]$. Planned comparisons revealed that Group NF nosed in the food site more than did Group FN during the presentation of the second lever $[t(14)=2.81]$ but not during the presentation of the first lever $[t(14)=1.78]$.

The results of Experiment 2 show that the congruent stimulus (Group FN) resulted in a sequence of predatory behavior directed to the elements of the serial CS. The rats first contacted the first ( $f a r$ ) lever and then contacted the second (near) lever and nosed in the food site. The incongruent stimulus (Group NF) resulted in a sequence of responding that largely avoided the second lever. These rats contacted the first (near) lever and then usually skipped contact with the second lever, preferring instead to nose in the food site during presentation of the second ( far) lever.

These outcomes were not very supportive of a more traditional associative account. Perhaps the biggest surprise was that the rats were so sensitive to a small difference in distance between the lever elements and the food. This sensitivity might bring to mind a traditional ingestive contrast effect in which animals are insensitive to absolute values of an incentive but very sensitive to relative values (Flaherty, 1982). But, in our experiment, there were no differences in what was ingested; this was a contrast effect produced by particular relations of the spatial distances and the temporal order of the stimuli preceding food.

Further, even assuming the observed high degree of sensitivity to spatial differences does little to improve the explanations of a more traditional view. The congruent serial CS leading from spatially far to near cues resulted in similar amounts of lever contact during presentation of both CS elements, instead of the exaggeration of more contact with the first lever element than with the second. Additionally, the incongruent stimulus leading from spatially near to far cues resulted in the exaggeration of lever contact to the first stimulus rather than the expected more equal distribution of responding. The one prediction supported was that the rats in Group FN exaggerated the difference between the two lever elements by nosing in the food site more during presentation of the second element than during presentation of the first.

In contrast, the behavior systems strategy of relating the characteristics of the serial CSs to predatory strings of behavior provided a reasonable basis for the finding that rats were sensitive to small differences in the relative proximity to food of moving stimuli. The notion of mapping between predatory strings of behavior and sequential search modes also could account for the outcomes of the different CSs. In both cases, the sequence of lever elements engaged a sequence of search modes and responses leading to food, but this sequence involved contact of both levers only when the second lever was spatially closer to the capture site. When the second lever was not closer to the capture site, the rats went straight to the capture site instead of chasing the moving lever. A similar failure of a rat to chase a moving stimulus predicting food was found using rolling ball bearings and a very short CS-US interval (Timberlake et al., 1982). More specifically, when ball bearing entry preceded food by $2.5 \mathrm{sec}$, the animals went to the food site rather than to the ball bearing. In both cases, the stimulus temporally proximate to the delivery of food more strongly elicited a focal search mode than it did the continuation of a general search mode.

In short, the present experiment showed that a serial CS with congruent spatial and temporal characteristics produced a different pattern of conditioned responding than did an incongruent stimulus. Apparently rats can be quite sensitive to the spatiotemporal aspects of an object, when differences either in the spatial distance (in the present case) or in the temporal distance (in the ball bearing case) are very slight. These results are compatible with the behavior systems view that responding to moving stimuli is organized and influenced by a sequence of search modes related to predatory behavior (Timberlake, 1994; Timberlake et al., 1982). The results were less supportive of predictions based on a more traditional associative view of conditioning. In particular, an optimal-interval account was not adequate to explain the distribution of nosing in the food site and contacting the levers.

\section{EXPERIMENT 3}

In Experiment 3, we attempted to further examine the behavior systems account of the results of Experiment 2 by testing a prediction that appears to differ from that of a more traditional associative view. The manipulation we examined was to systematically and extensively increase the duration of the second element of the serial CS, following Experiment 2 (from 4 to $28 \mathrm{sec}$ in increments of $4 \mathrm{sec}$ ). On the basis of a more traditional associative view, there are two possible outcomes of this manipula- 

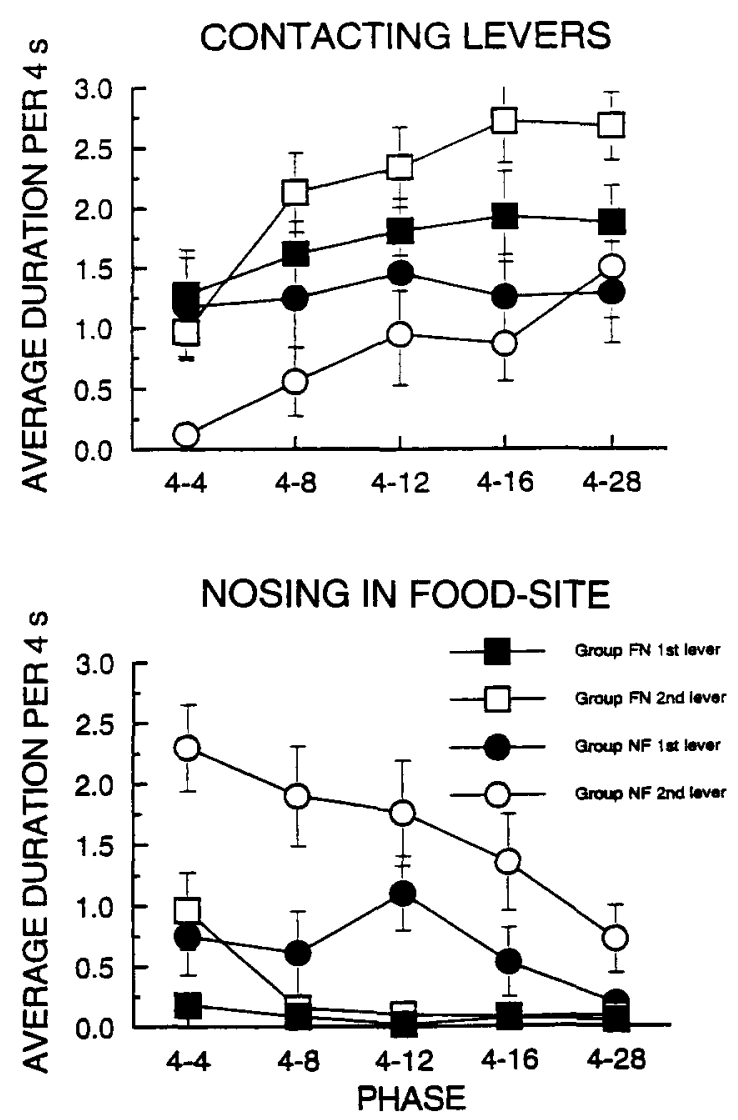

Figure 4. The average duration ( $\pm S E M$ ) spent contacting the far and near levers (top panel) and nosing in the food site during the presentation of the far and near levers (bottom panel) per 4 sec across the different phases of Experiment 3.

tion. Either increasing the duration of the second lever element should extend the behavior that occurred to the $4-\mathrm{sec}$ stimulus across the duration of the lengthened presentation of the stimulus, or it should decrease the behavior controlled by the second stimulus, because extinction or inhibition of delay occurred or the optimal interval of conditioning was surpassed. A similar prediction of decreasing behavior might be made from the assumptions of scalar expectancy theory (SET). As the duration of a CS increases without an increase in the IFI, weaker responding to the CS should occur (Gibbon \& Balsam, 1981). We assume that, because the first lever is moving even further from food as the duration of the second lever is increased, responding should weaken even further.

There still remains the difficulty of specifying how these predictions should relate to the different CRs we have been measuring. Traditional associative theory lacks clear performance rules for mapping associative strength to the form of a CR. Given the results in the previous experiments, we assume that any decrease in responding should occur most rapidly for nosing in the food site. It might be argued that lever contact could maintain itself for a longer period of time because the optimal interval for this response is slightly longer than the interval for nosing in the food site (although the optimal-interval explanation did not deal well with the lever contact results of Group NF in Experiment 2).

Different predictions emerge from the behavior systems concept of conditioned search modes. In this view, increasing the duration of the second element should change the relation between presentation of the lever elements and the motivational modes (see Figure 1). Lengthening the duration of the second lever should differentially increase conditioning of a general search mode relative to a focal search mode for both congruent and incongruent serial CSs. Thus, in terms of responding during the presentation of the second lever, there should be an increase in lever-directed behavior, as well as a relative decrease in the overall amount of nosing in the food site.

Two outcomes are possible with respect to responding during the presentation of the first lever. If the progressive increase in the duration of the second lever causes the first lever to become mapped exclusively to a general search mode, the animal may show less contact to the first lever and more general locomotor search. However, if increasing the duration of the second lever systematically allows the first lever to remain linked to the search modes that it initially controlled, responding to the first lever should remain relatively unchanged.

Finally, increasing the duration of the second lever element should allow its temporal characteristics to dominate the importance of its spatial characteristics, making the congruent and incongruent serial CSs more similar. Thus, as the duration of the second stimulus increases, we expect a decrease in the differences in the pattern of responding between Groups FN and NF.

\section{Method}

Subjects. The animals and housing conditions were the same as those used in Experiment 2.

Apparatus and Procedure. The apparatus and general procedures were the same as those used in Experiment 2, except that the second lever was presented for $8 \mathrm{sec}$ ( 12 sessions), $12 \mathrm{sec}(6$ sessions), $16 \mathrm{sec}$ ( 6 sessions), and $28 \mathrm{sec}$ ( 6 sessions). The duration of the second lever was increased when responding had stabilized in a particular phase. Stability was assessed by visual inspection of the graphical representation of the average duration spent contacting the lever and nosing in the food site (see Kazdin, 1982).

\section{Results and Discussion}

The top graph in Figure 4 shows the average duration spent contacting the levers during the last 2-day block of each phase. An ANOVA confirmed that, overall, both groups spent more time contacting the levers as the second lever was presented for longer durations $[F(4,56)=$ 11.28], and Group FN contacted the levers more than did Group NF $[F(1,14)=5.31]$. There was, however, a marginal interaction between groups and the duration of the second lever $[F(4,56)=2.52, p=.05]$, and there was a marginal interaction among group, the duration of the second lever, and the order in which the levers were presented $[F(4,56)=2.40, p<.06]$. Planned comparisons 
of the second lever during the 4-sec condition with contacts to this lever collapsed across all other durations showed that increasing the duration of the second lever caused both Group FN and Group NF to spend more time contacting this lever $[t \mathrm{~s}(7)=4.37$ and 2.39 , respectively]. Similar planned comparisons of the first lever during the 4-sec condition with contacts to this lever collapsed across all other durations showed that increasing the duration of the second lever caused Group FN but not Group NF to spend more time contacting the first lever $[t \mathrm{~s}(7)=3.95$ and 1.81 , respectively].

The bottom graph in Figure 4 shows the average duration spent nosing in the food site during the last 2-day block of each phase. An ANOVA confirmed that, overall, both groups nosed in the food site less as the second lever was presented for longer durations $[F(4,56)=10.08]$, that Group NF nosed in the food site more than did Group FN $[F(1,14)=11.33]$, and that there was more nosing in the food site during the presentation of the second than during that of first lever $[F(1,14)=64.95]$. There were also significant interactions between group and the duration that the second lever was available $[F(4,56)=3.64]$, between group and the order in which the levers were presented $[F(1,14)=32.65]$, and between the duration of the second lever and the order in which the levers were presented $[F(4,56)=5.61]$. Fisher's least significant difference (LSD) test showed that, in general, increasing the duration of the second lever caused Group NF, but not Group FN, to spend less time nosing in the food site.

In sum, the results from Experiment 3 showed that increasing the duration of the second lever, thereby making its onset more temporally distant from food, produced an overall increase in lever contact and a decrease in nosing in the food site. As in Experiment 2, the congruent stimulus (Group FN) showed different effects of the manipulation than did the incongruent stimulus (Group NF). Specifically, Group FN showed a progressive increase in lever contact during both levers, whereas Group NF showed an increase in contact only to the second lever. Moreover, Group FN generally nosed in the food site less than did Group NF during presentation of both levers. These results are consistent with the view that increasing the duration of the second serial element caused it to become increasingly mapped to a general search mode, producing a conditioned search state characteristic of earlier parts of a predatory sequence.

From a more traditional associative view, increasing the duration of the presentation of the second element should have produced no change or less responding during presentation of this element because the food was more temporally distant, thereby weakening associations and/or producing inhibition of delay. Also, increasing the ratio of the duration of the CS to the IFI should have produced a decrement in conditioned responding. The data supported this decremental prediction for nosing in the food site but failed to support the prediction for lever contact. However, perhaps it could be argued that the optimal interval for lever conditioning was increased by the relatively small increments in the duration of the second lever. We will address this possibility in Experiment 4B.

\section{EXPERIMENT 4A}

Experiment 3 showed that increasing the duration of the second lever resulted in (1) more responding to the second lever, regardless of its spatial location, and (2) less nosing in the food site. Although the data were compatible with the behavior systems approach, two alternative explanations that focus on typical associative variables were considered in the following two experiments.

One alternative explanation of the results of Experiment 3 is that the changes in behavior across the increases in duration of the second lever were simply due to an increase in the number of training trials, rather than to an increase in the duration of the second lever. This explanation seems questionable as a general account of the data of Experiment 3, if only because the duration of the second lever was increased only when responding had stabilized at the previous duration; nonetheless, the length of training seemed worth evaluating as a contributor to the effect shown in Experiment 3.

To remove the potential confounding of number of training trials and increases in duration of the second lever, Experiment $4 \mathrm{~A}$ presented a new group of rats with an incongruent stimulus (NF) in which the initial condition of Experiment 3 (i.e., one in which each lever was presented for $4 \mathrm{sec}$ ) was maintained for a number of sessions that was close to the total received by the rats in Experiment 3 (i.e., 42 sessions in Experiment 3 vs. 38 sessions in Experiment 4A). If the number of trials was the key to the effects in Experiment 3, rather than the increased duration of the second lever, the patterns of changes in lever contact and nosing in the food site over trials in the present experiment should resemble those in Experiment 3.

\section{Method}

Subjects. The animals were 8 female Sprague-Dawley rats that were approximately 90 days old at the start of the experiment. The housing conditions were the same as those used in Experiments 1, 2 , and 3 .

Apparatus and Procedure. The apparatus, general procedures, and dependent measures were the same as those used in Experiment 2, except that, because of technical difficulties, training continued for 38 rather than 42 sessions.

\section{Results and Discussion}

The top graph in Figure 5 shows the average duration spent contacting the levers during the following 2-day blocks: Sessions 11 and 12, 23 and 24, 29 and 30, and 33 and 34 . These correspond closely to the 2-day blocks analyzed in Experiment 3. An ANOVA showed that, overall, the rats spent marginally more time contacting the levers as training continued $[F(3,21)=2.98, p<.06]$ and that they contacted the first lever marginally more than the second $[F(1,7)=5.29, p<.06]$. There was no interaction between session and the order in which the levers were presented $[F(3,21)=0.80]$. 

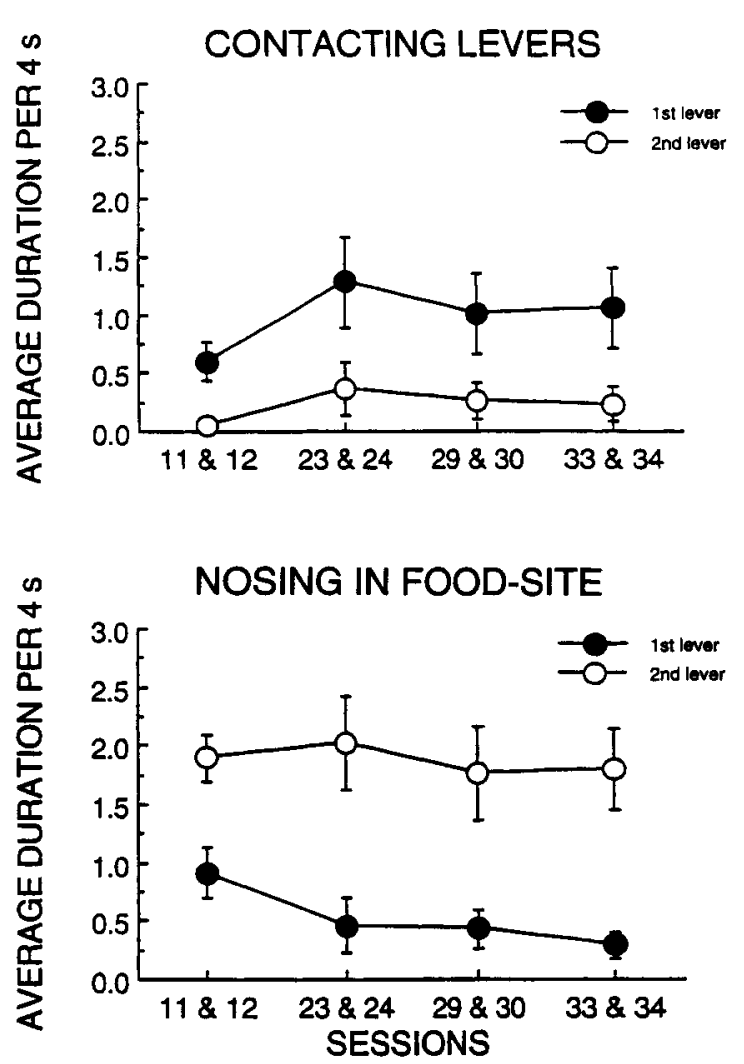

Figure 5. The average duration ( $\pm S E M$ ) spent contacting the near and far levers (top panel) and nosing in the food site during presentation of the near and far levers (bottom panel) during blocks of Sessions 11 and 12, 23 and 24, 29 and 30 , and 33 and 34 during the incongruent stimulus (Group NF).

The bottom graph in Figure 5 shows data from nosing in the food site during the same sessions as those in the top graph. An ANOVA confirmed that, overall, nosing in the food site did not change with prolonged training $[F(3,21)=0.97]$, but there was more nosing in the food site during presentation of the second ( far ) than during that of the first (near) lever $[F(1,7)=28.60]$. There was no interaction between session and the order in which the levers were presented $[F(3,21)=1.70]$.

Although there was a trend toward an increase in responding to the first lever with extended training, the change in lever contact appears to be considerably less than the changes occurring during Experiment 3 (compare the top panels of Figures 4 and 5). Moreover, whereas extending the duration of the second lever in Experiment 3 promoted contact with this lever, extended training alone in the present experiment failed to produce a change in contact with the second lever. Thus, extended training with the incongruent stimulus cannot have been responsible for the results observed in Experiment 3.

\section{EXPERIMENT 4B}

The purpose of Experiment $4 \mathrm{~B}$ was to determine the importance of incremental shaping of responding during small systematic increases in the duration of the second lever element in producing the results of Experiment 3. For example, in Experiment 3, incremental shaping might have extended the optimal conditioning interval for lever contact to $28 \mathrm{sec}$. To test this, Experiment 4B used two new groups of rats exposed only to the terminal condition of Experiment 3 (i.e., a 4 -sec lever followed by a 28 -sec lever). In the absence of prior training with shorter intervals and because of the relatively long time between the presentations of the levers and food, there should be fewer differences between the congruent and incongruent stimuli. Also, if prior training with shorter durations of the second element provided more support for a focal search mode in the final condition or more explicit conditioning of nosing in the food site, we would expect less nosing in the food site during presentation of both levers.

\section{Method}

Subjects. The animals were 16 female Sprague-Dawley rats that were approximately 90 days old at the start of the experiment. The housing conditions were the same as those used in Experiments 1, 2 , and 3 .

Apparatus and Procedure. The apparatus, general procedures, and dependent measures were the same as those used in Experiment 2 , except that the second lever was presented for $28 \mathrm{sec}$ for 10 sessions.

\section{Results and Discussion}

The top graph in Figure 6 shows the average duration spent contacting the levers during the last 2-day block of conditioning. An ANOVA showed that both groups spent similar amounts of time contacting the levers $[F(1,14)=$ 0.23 ] and that they contacted the second lever more than they did the first $[F(1,14)=6.09]$. There was no interaction between group and the order in which the levers were presented $[F(1,14)=2.56]$.

The bottom graph in Figure 6 shows the average duration spent nosing in the food site during the last 2-day block of conditioning. An ANOVA confirmed that both groups spent similar amounts of time nosing in the food site $[F(1,14)=0.05]$, regardless of the order in which the levers were presented $[F(1,14)=0.83]$. There was no interaction between the group and the order in which the levers were presented $[F(1,14)=3.57]$.

In sum, the results showed more contact with the second lever than with the first and similar conditioned responding to the congruent and incongruent serial stimuli. This pattern of responding resembled closely the results of the terminal condition of Experiment 3, thus providing little evidence that the effects in the terminal condition of this experiment were markedly affected by earlier training and incremental shaping. The lever contact data provide little support for a more traditional associative view. Instead, they support the hypothesis that temporally distant cues come to differentially control a general search mode.

\section{GENERAL DISCUSSION}

The results of these experiments showed that rats respond to the temporal order of a two-element serial CS 

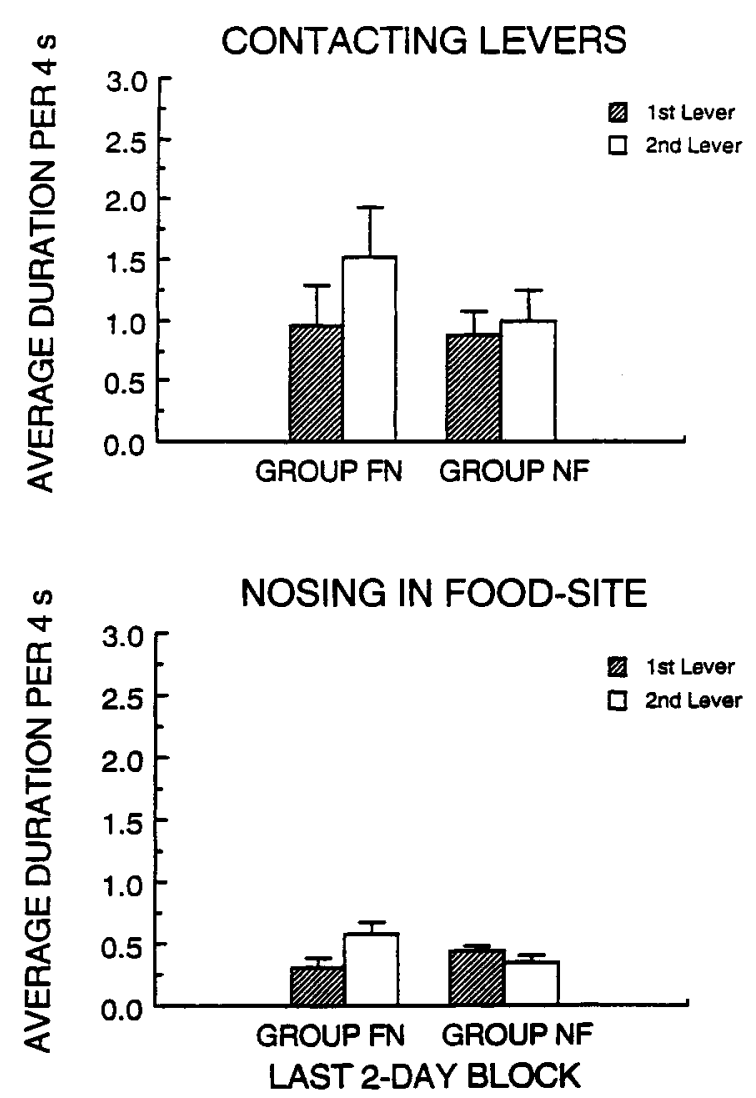

Figure 6. The average duration ( $\pm S E M$ ) spent contacting the far and near levers (top panel) and nosing in the food site during presentation of the far and near levers (bottom panel) per 4 sec for Groups FN and NF in Experiment 4B.

and to very small differences in the spatial distance of CS elements from the food site, provided that both elements are presented to each rat. In Experiment 1, a group of rats receiving two 4-sec presentations of the far lever did not behave differently from a group receiving two 4 -sec presentations of the near lever. Both groups showed the same temporal differences in behavior, contacting the first lever more than the second and nosing in the food site more during presentation of the second lever. The absence of a spatial effect in Experiment 1 was not surprising, given the small difference in the distances between the near and far levers and the food site $(2.5 \mathrm{~cm})$. However, the absence of a spatial effect does contrast with the voluminous literature showing that quite small absolute differences in the temporal relationship between a CS and a US can have a profound effect on conditioned responding (see Mackintosh, 1983). Experiment 2, however, showed a marked effect of a small spatial difference when the rats were exposed to both lever-food-site differences (i.e., the near and far levers) during the same serial CS.

Rats that received a congruent sequence of elements (Group FN) differed markedly in their distribution of responding across the lever elements from the pattern produced by the incongruent sequence of elements (Group
NF). For the congruent serial CS, the spatial proximity of the two elements to the food site was positively correlated with their temporal proximity to food delivery (i.e., the far lever was followed by the near lever and then by food). In the incongruent serial stimulus, the spatial proximity of the two elements to the food site was negatively correlated with their temporal proximity to the food site (i.e., the near lever was followed by the far lever and then by food). For the first lever, the rats showed similar levels of contact of the far lever (Group FN) and near lever (Group NF). In the case of the second lever, the rats contacted the near lever (Group FN) much more than they did the far lever (Group NF) and nosed in the food site more during presentation of the far lever than during presentation of the near. Increasing the duration of the second lever in Experiments 3 and 4B produced a marked increase in lever contact during the presentation of the second lever. These results were not due simply to a larger number of trials or the shaping effects of previous conditioning (see Experiments $4 \mathrm{~A}$ and $4 \mathrm{~B}$ ).

\section{A Behavior Systems Account}

The results were largely consistent with a behavior systems account that posits a sequence of search modes leading to food. Each mode is presumed to be related to a particular repertoire of perceptual-motor organization (combinations of stimulus sensitivities and response components), and the different modes interact to produce a search state that controls responding. A string of appetitive behavior begins under predominant control of a general search mode and consists of general exploratory responses and systematic attention to the environment, particularly to food-related stimuli. As better predictors for food emerge, the focal search mode becomes more engaged, followed by increased activity in the handling/ consuming mode as food arrives. The latter part of this sequence is accompanied by a shift in the response repertoire toward food-site-directed behavior and then toward behavior directed at food itself. Stimulus characteristics of a CS, such as spatial distance and temporal proximity to food-as well as movement, sound, size, scent, and texture-influence the mode that is conditioned and the expression of the different responses.

In the present circumstances, the spatial qualities of the sequence of moving levers suggested that a congruent serial CS should produce a different pattern of behavior to the CS elements than would an incongruent serial $\mathrm{CS}$. In the congruent case (Group FN), the movement caused by the insertion of the levers, in combination with the fact that the successive levers became spatially closer to the food site, engaged a general search mode preychasing mechanism, resulting in approach to and contact with both the first and the second levers. However, for Group NF, the insertion of both levers fit well with the general search mode, but, because the second lever's spatial characteristics took the animal farther away from the food site (relative to the characteristics of the first lever), it did not sufficiently engage the prey-chasing mecha- 
nism of this mode at such a close temporal proximity to food. The outcome was weaker conditioning of the general search mode and an increase in nosing in the food site supported by the temporal proximity of the second element to food. It seems that rats will "chase" the FN sequence of levers because the levers became closer to the food site on successive appearances but will not "chase" the NF sequence of levers because these levers became farther from the food site on successive appearances.

An important quality of the behavior systems approach was the ability to readily conceptualize multiple CSrelated responses within a string of appetitive behavior and to relate them to the elements of the CS. Perhaps the most interesting prediction of this approach was that, as the duration of the second lever was increased, the animal should increase its interaction with that lever (while decreasing its nosing in the food site) because the increased duration of the second lever began to better support conditioning of a general search mode. This prediction was supported whether the longer duration of the second lever was produced by increments after initial training with shorter intervals (Experiment 3 ) or put in effect from the beginning (Experiment 4B).

\section{Associative Accounts}

In Experiment 1, a more traditional associative account predicted the effects of a serial CS on nosing in the food site. Differential excitatory strength resulting from the temporal proximity of the second CS element to food should result in a stronger $\mathrm{CR}$. Consistent with this prediction, nosing in the food site was greater during presentation of the second lever than during presentation of the first. But this prediction, shared with the behavior systems approach, was the only a priori prediction.

A basic problem with traditional associative theory is how to predict which of the responses in the animals' repertoire will emerge as the CR. As a result, it was difficult to predict the emergence of a second CR (lever contact), much less its pattern of expression. Although the amount of lever contact in Experiment 1 was unimpressive in amount, the pattern of responding across lever elements was the opposite of that for nosing. A post hoc associative account that can explain the overall results of Experiment 1 is that the optimal interval for lever contact was slightly longer than the optimal interval for nosing in the food site, thereby accounting for the decline in lever contact and the rise in nosing in the food site from the first CS element to the second.

The results of Experiment 2, however, yielded a pattern of responding to the levers that was the opposite of what one would predict on the basis of an optimal temporal interval and spatial distance for conditioning to the second lever. The congruent serial stimulus should have enhanced the pattern of contacting the first lever, rather than the second, because the first was both temporally and physically distant, whereas the second was both temporally and physically proximate. However, lever contact was similar during the two elements. The incongruent serial stimulus should have produced more equal lever contact in the first and second CS elements but instead showed the maximum enhancement of the pattern shown in Experiment 1 -contact to the first element and little contact to the second.

The results of Experiment 3 also presented problems for even the optimal-interval account. The increase in contact with the second lever as a function of increases in its duration is difficult to explain, unless we assume that the optimal interval for conditioning lever contact is at least $28 \mathrm{sec}$. However, no research supports such an assumption. Further, the optimal-interval argument did not explain why lever contact differed so markedly between congruent and incongruent sequences during the 4-sec duration of the second lever. Finally, Experiments $4 \mathrm{~A}$ and $4 \mathrm{~B}$ showed that several traditional associative variables, including number of training trials, previous type of training, and incremental shaping procedures, did not determine the results of Experiment 3.

\section{Conclusions}

On the basis of the present and other examples, we conclude that responding during Pavlovian serial conditioning is strongly influenced by a preorganized sequence of search modes related to the US (Domjan, 1994; F. J. Silva et al., 1998; F. J. Silva et al., 1996; Timberlake, 1994). Different levels of nosing in the food site and contacting the lever were observed during the elements of the serial $\mathrm{CS}$ as a function of whether rats were presented with a congruent or an incongruent stimulus. A congruent CS is one in which the spatial and temporal proximities of the serial elements are positively correlated. Such a stimulus possess qualities of a moving prey item that is chased and captured. An incongruent CS is one in which the spatial and temporal proximities of the serial elements are negatively correlated. Such a stimulus may be moving in the direction of escaping prey, rather than being a prey item that will be captured soon at the food site. Increasing the duration of the second lever increased responding to that lever and considerably reduced the difference in responding to congruent and incongruent serial stimuli. These effects question the sufficiency of traditional explanations based only on the temporal or the spatial proximity of the CS and the US and highlight the importance of the motivational and perceptual-motor organization a particular species brings to a situation (F. J. Silva et al., 1998; F. J. Silva et al., 1996; Timberlake, 1994; Timberlake \& K. M. Silva, 1995).

A longstanding ambiguity in associative theory, how to translate constructs such as associative strength into performance, emerged under the present procedures (Rescorla, 1988; Timberlake \& F. J. Silva, 1994). Most associative constructs are clearest when their analysis is restricted to a single $\mathrm{CR}$, but, in the present circumstances, multiple CRs emerged. We suspect the occurrence of multiple CRs is not atypical, although their emergence may be more obvious when there are multiple CS elements. A complete theory of conditioning requires what 
is often referred to as a set of performance rules. We tend to think that the distinction between associative rules and performance rules is too sharp. A better approach might be to combine the associative and performance labels in a single theory of conditioning.

Finally, we acknowledge that, given the large number of associative mechanisms developed by researchers over the last 100 years, it is likely that a combination of constructs can be assembled to explain the effects shown in the present experiments (see, e.g., Marshall, Gokey, Green, \& Rashotte, 1979; Rescorla \& Cunningham, 1979; Testa, 1975). Although we were not able to develop such an account, it clearly would be of interest. Most important, however, it seems unlikely to us that the explanatory constructs could be identified ahead of time without making assumptions beyond associationism (see Gallistel, 1990, for a similar discussion). It has proven to be surprisingly difficult for traditional associative theory to develop a predictive model of conditioning that applies in unfamiliar circumstances. As Timberlake $(1990,1997)$ argued, the apparent simplicity and comprehensiveness of associative laws may have been purchased by incorporating species-typical preorganization into the design of the apparatus, procedures, and measurements of successful learning paradigms. When we move outside these carefully formed circumstances, the predictive power of the traditional associative approach is lessened.

\section{REFERENCES}

Akins, C. K., Domjan, M., \& GutiérRez, G. (1994). Topography of sexually conditioned behavior in male Japanese quail (Coturnix japonica) depends on the CS-US interval. Journal of Experimental Psychology: Animal Behavior Processes, 20, 199-209.

Aron, A., \& Aron, E. N. (1994). Statistics for psychology. Englewood Cliffs, NJ: Prentice-Hall.

BAUM, W. M. (1974). On two types of deviation from the matching law: Bias and undermatching. Journal of the Experimental Analysis of Behavior, 22, 231-242.

Bowe, C. A. (1984). Spatial relations in animal learning and behavior. Psychological Record, 34, 181-209.

Breland, K., \& Breland, M. (1961). The misbehavior of organisms. American Psychologist, 16, 681-684.

CraIG, W. (1918). Appetites and aversions as constituents of instincts. Biological Bulletin, 34, 91-107.

Domjan, M. (1994). Formulation of a behavior system for sexual conditioning. Psychonomic Bulletin \& Review, 1, 421-428.

FLA HERTY, C. F. (1982). Incentive contrast: A review of behavioral changes following shifts in reward. Animal Learning \& Behavior, 10, 409-440.

Gallistel, C. R. (1990). The organization of learning. Cambridge, MA: MIT Press.

Gibbon, J., \& Balsam, P. (1981). Spreading association in time. In C. M. Locurto, H. S. Terrace, \& J. Gibbon (Eds.), Autoshaping and conditioning theory (pp. 218-253). New York: Academic Press.

HerRnStein, R. J. (1970). On the law of effect. Journal of the Experimental Analysis of Behavior, 13, 243-266.

Howel., D. C. (1997). Statistical methods for psychology (4th ed.). Belmont, CA: Duxbury.

Hull, C. L. (1952). A behavior system. New Haven, CT: Yale University Press.

KazDin, A. E. (1982). Single-case research designs. New York: Oxford University Press.

KEHOE, E. J., \& NAPIER, R. M. (1991). Real-time factors in the rabbit's nictitating membrane response to pulsed and serial conditioned stimuli. Animal Learning \& Behavior, 19, 195-206.
Kimble, G. A. (1961), Hilgard and Marquis' Conditioning and learning (2nd ed.). New York: Appleton-Century-Crofts.

KonORSK1, J. (1967). Integrative activity of the brain. Chicago: University of Chicago Press.

LuCas, G. A., Timberlake, W., \& Gawley, D. J. (1988). Adjunctive behavior of the rat under periodic food delivery in a 24-hour environment. Animal Learning \& Behavior, 16, 19-30.

MACKINTOSH, N. J. (1983). Conditioning and associative learning. Oxford: Oxford University Press.

Marshall, B. S., Gokey, D. S., Green, P. L., \& Rashotte, M. E. (1979). Spatial location of first- and second-order visual conditioned stimuli in second-order conditioning of the pigeon's keypeck. Bulletin of the Psychonomic Society, 13, 133-136.

MAson, G. A. (1991). Stereotypies: A critical review. Animal Behaviour, 41, 103-115.

RESCORLA, R. A. (1988). Pavlovian conditioning: It's not what you think it is. American Psychologist, 43, 151-160.

Rescorla, R. A., \& CunNingham, C. L. (1979). Spatial contiguity facilitates Pavlovian second-order conditioning. Journal of Experimental Psychology: Animal Behavior Processes, 5, 152-161.

Schneiderman, N., \& Gormezano, 1. (1964). Conditioning of the nictitating membrane of the rabbit as a function of the CS-US interval. Journal of Comparative \& Physiological Psychology, 69, 188-195.

SEVENSTER, P. (1973). Incompatibility of response and reward. In R. A. Hinde \& J. Stevenson-Hinde (Eds.), Constraints on learning: Limitations and predispositions (pp. 265-283). New York: Academic Press.

Silva, F. J., Timberlake, W., \& CEVIK, M. O. (1998). A behavior systems approach to the expression of excitatory backward associations. Learning \& Motivation, 29, 1-22.

Silva, F. J., Timberlake, W., \& KoEhler, T. L. (1996). A behavior systems approach to bidirectional excitatory serial conditioning. Learning \& Motivation, 27, 130-150.

Silva, K. M., \& TimberlaKe, W. (1997), A behavior systems view of conditioned states during long and short CS-US intervals. Learning \& Motivation, 28, 465-490.

SKINNER, B. F. (1948). "Superstition" in the pigeon. Journal of Experimental Psychology, 38, 168-172.

Staddon, J. E. R., \& Horner, N. M. (1989). Stochastic choice models A comparison between Bush-Mosteller and a source-independent reward-following model. Journal of the Experimental Analysis of Behavior, 52, 57-64.

Sraddon, J. E. R., \& Simmel hag, V. L. (1971). The "superstition" ex periment: A reexamination of its implications for the principles of adaptive behavior. Psychological Review, 78, 3-43.

Stephens, D. W., \& Krebs, J. R. (1986). Foraging theory. Princeton, $\mathrm{NJ}$ : Princeton University Press.

TERrace, H. S. (1984). Simultaneous chaining: The problem it poses for traditional chaining theory. In M. L. Commons, R. J. Herrnstein, \& A. R. Wagner (Eds.), Quantitative analysis of behavior: Vol. 4. Discrimination processes (pp. 115-138). Cambridge, MA: Ballinger.

TESTA, T. J. (1975). Effects of similarity of location and temporal intensity pattern of conditioned and unconditioned stimuli on the acquisition of conditioned suppression in rats. Journal of Experimental Psychology: Animal Behavior Processes, 1, 114-121.

TIMBERLAKE, W. (1980). A molar equilibrium theory of learned performance. Psychology of Learning \& Motivation, 14, 1-58.

TIMBERLAKE, W. (1990). Natural learning in the laboratory. In D. A. Dewsbury (Ed.), Contemporary issues in comparative psychology (pp. 31-54). Sunderland, MA: Sinauer.

TiMBERLAKE, W. (1993). Behavior systems and reinforcement: An integrative approach. Journal of the Experimental Analysis of Behavior. 60, 105-128.

TimBERLAKE, W. (1994). Behavior systems, associationism, and Pavlovian conditioning. Psychonomic Bulletin \& Review, 1, 405-420.

TimberlaKe, W. (1997). An animal-centered, causal-system approach to the understanding and control of behavior. Applied Animal Behaviour Science, 53, 107-129.

TimberlaKe, W., \& LuCAS, G. A. (1985). The basis of superstitious behavior: Response contingency, stimulus substitution, or appetitive behavior? Journal of the Experimental Analysis of Behavior, 44, 279-299.

Timberlake, W., \& Lucas, G. A. (1989). Behavior systems and learning: From misbehavior to general principles. In S. B. Klein \& R. R. 
Mowrer (Eds.), Contemporary learning theories: Instrumental conditioning theory and the impact of biological constraints on learning (pp. 237-275). Hillsdale, NJ: Erlbaum.

Timberlake, W., \& LuCas, G. A. (1991). Periodic water, interwater interval, and adjunctive behavior in a 24 -hour multiresponse environment. Animal Learning \& Behavior, 19, 369-380.

TimberlaKe, W., \& Silva, F. J. (1994). Observation of behavior, inference of function, and the study of learning. Psychonomic Bulletin \& Review, 1, 73-88.

TimberlaKe, W., \& Silva, K. M. (1995). Appetitive behavior in ethology, psychology, and behavior systems. In N. Thompson (Ed.), Perspectives in ethology: Vol. 11. Behavioral design (pp. 211-253). New York: Plenum.
Timberlake, W., Wahl, G., \& King, D. (1982). Stimulus and response contingencies in the misbehavior of rats. Journal of Experimental Psychology: Animal Behavior Processes, 8, 62-85.

TINBERGEN, N. (1951). The study of instinct. Oxford: Oxford University Press.

Tolman, E. C. (1932). Purposive behavior in animals and men. New York: Century.

Williams, D. R., \& Williams, H. (1969). Automaintenance in the pigeon: Sustained pecking despite contingent non-reinforcement. Journal of the Experimental Analysis of Behavior, 12, 511-520.

(Manuscript received August 19, 1997; revision accepted for publication February 5, 1998.)

\section{9th Annual Meeting of the Psychonomic Society Dallas, Texas November 19-22, 1998}

The 39th Annual Meeting of the Psychonomic Society will be held in Dallas, Texas, at the Wyndham Anatole Hotel. Registration will begin on Thursday evening, November 19. A poster session will be held on Thursday evening; spoken sessions will begin on the morning of Friday, November 20 . Sessions will continue through noon on Sunday, November 22.

Programs and hotel reservation cards will be mailed to members and associates in September. Additional programs will be available at the meeting registration desk for $\$ 10.00$.

For further information, please contact the Secretary-Treasurer of the Society: Roger L. Mellgren, Department of Psychology, Box 19528, University of Texas, Arlington, TX 76019-0528 (phone: 817-272-2775; fax: 817-272-2364; e-mail: mellgren@uta.edu). 